\title{
Gêneros oclusos na telecolaboração: a variação na estrutura retórica da sessão oral de teletandem inicial
}

DOI: http://dx.doi.org/10.21165/el.v48i3.2175

\section{Laura Rampazzo'}

\section{Resumo}

O projeto Teletandem Brasil (TELLES, 2006) proporciona a estudantes universitários o contato intercultural entre falantes de línguas distintas em um ambiente telecolaborativo em que cada participante auxilia seu par na aprendizagem de sua língua. O presente artigo apresenta os resultados de uma investigação da estrutura retórica de um evento comunicativo que ocorre neste contexto, a sessão oral de teletandem inicial (SOTi), compreendida como um gênero (RAMPAZZO; ARANHA, 2018, 2019b), a fim de verificar se há relação entre a variação em sua estrutura e o fato de os participantes não terem acesso ou experiência anterior com esse evento comunicativo nem conhecimento de sua estrutura retórica esperada, considerando que a SOTi possa ser um gênero ocluso (LOUDERMILK, 2007; SWALES, 1996). Nossos resultados indicam que a variação pode estar associada à oclusão da SOTi, uma vez que os participantes devem recorrer a outros gêneros e experiências prévias para a produção da sessão oral de teletandem inicial.

Palavras-chave: telecolaboração; gêneros oclusos; estrutura retórica.

1 Instituto Federal de Educação, Ciência e Tecnologia de São Paulo (IFSP), Barretos, São Paulo, Brasil; laura.rampazzo@ifsp.edu.br; https://orcid.org/0000-0002-4736-9900 


\title{
Occluded genres in telecollaboration: the variation in the rhetorical structure of the initial teletandem oral session
}

\begin{abstract}
The project Teletandem Brasil (TELLES, 2006) allows university students to experience intercultural contact with speakers of different languages in a telecollaborative environment in which each participant assists his/her partner in learning the language of one another. This article presents the results of an investigation of the rhetorical structure of a communicative event that occurs in such context, the initial teletandem oral session (iTOS), considered a genre (RAMPAZZO; ARANHA, 2018, 2019b), in order to verify if there is any relation between the variation in its structure and the fact that participants had not had previous access to this communicative event neither are aware of its expected rhetorical structure, given that iTOS can be an occluded genre (LOUDERMILK, 2007; SWALES, 1996). Our results indicate that the variation may be associated with iTOS occlusion, in view of the fact that participants need to resort to other genres and previous experiences to be able to engage in the initial teletandem oral session.
\end{abstract}

Keywords: telecollaboration; occluded genres; rhetorical structure.

\section{Introdução}

É consenso entre autores da área de Linguística Aplicada e Computer assisted language learning $(C A L L)^{2}$ que o avanço de tecnologias digitais provocou mudanças no uso de computadores em contextos pedagógicos, como indicam Hauck e Youngs (2008), culminando no surgimento de projetos telecolaborativos, os quais permitem, segundo O'Dowd (2013), o contato intercultural virtual entre aprendizes de línguas estrangeiras distantes geograficamente.

O projeto Teletandem Brasil (TELLES, 2006) surge em meio a esses avanços. Trata-se de um projeto telecolaborativo baseado no tandem (BRAMMERTS, 1996) que promove o contato virtual de estudantes universitários da UNESP, campi de São José do Rio Preto, Assis e Araraquara, que estudam uma língua estrangeira (o inglês, no caso do campus de São José do Rio Preto), com estudantes universitários estrangeiros que estudam a língua portuguesa. Desse modo, são formados pares de participantes que se auxiliam na aprendizagem da língua do outro. Esses pares encontram-se semanalmente por meio de ferramentas de comunicação síncrona, como o Skype, em sessões orais de teletandem (SOTs) por um período variado de semanas, a depender dos arranjos das parcerias.

2 Aprendizagem de línguas assistida por computador. 
Uma vez que é baseado no tandem, a prática de teletandem deve envolver três princípios, tais como postos em Vassallo e Telles (2006), a saber: (i) separação de línguas ${ }^{3}$ - os encontros virtuais são igualmente divididos em duas partes para prática dos idiomas de uma parceria; (ii) autonomia - os participantes são autônomos o bastante para definirem com o parceiro suas metas e processo de aprendizagem; (iii) reciprocidade os participantes investem igualmente na aprendizagem um do outro e alternam-se nos papéis de tutores de sua própria língua e aprendizes da língua do outro.

Ao longo dos anos, o projeto desenvolveu-se em diferentes modalidades ${ }^{4}$, dentre as quais a de teletandem institucional integrado (TTDii) (ARANHA; CAVALARI, 2014), que tem como característica ser reconhecida pelas instituições parceiras e ser integrada às disciplinas de línguas nas duas universidades. Assim, a participação torna-se obrigatória aos estudantes matriculados nas disciplinas, os professores responsáveis atribuem uma nota aos alunos e as sessões orais ocorrem no horário de aula das disciplinas em local apropriado. A participação no TTDii ainda envolve a realização de macro e micro-tarefas ${ }^{5}$ (ARANHA; LEONE, 2017) e a coleta sistêmica de dados entre todos participantes do grupo que autorizaram o acesso aos seus dados produzidos no contexto (ARANHA; LUVIZARIMURAD; MORENO, 2015; LOPES, 2019).

Em relação às tarefas, Aranha (2014) argumenta que elas podem corresponder a gêneros que se inter-relacionam em um sistema para o cumprimento dos propósitos da comunidade teletandem (RAMPAZZO; ARANHA, 2019a; SILVA, 2012), a partir da abordagem de gênero de Inglês para Fins Específicos, que compreende os gêneros como eventos comunicativos de estrutura retórica padronizada, os quais servem aos propósitos comunicativos de uma comunidade discursiva (SWALES, 1990).

A fim de averiguar se a sessão oral de teletandem inicial (SOTi) pode ser caracterizada como um gênero do sistema, Rampazzo e Aranha $(2018,2019 b)$ apresentam a estrutura retórica dos primeiros 15 minutos de dez sessões orais de teletandem iniciais e

3 Recentemente, passou-se a discutir a respeito do nome do princípio de separação de línguas. Em publicação de 2019, por exemplo, Evangelista e Salomão já indicam que o princípio pode também ser chamado de princípio da igualdade.

4 Outros trabalhos discutem as diferentes modalidades de teletandem, tais como, Aranha e Cavalari (2014), Zakir (2015), Cavalari e Aranha (2016), Rampazzo e Aranha (2019a).

5 Ver Aranha e Leone (2017) para uma descrição mais extensa das tarefas no teletandem. Em linhas gerais, há duas macro-tarefas: a sessão oral de teletandem (SOT) (encontros virtuais) e a mediação. Associadas às SOTs estão as micro-tarefas de troca de textos (estudantes escrevem textos na língua-alvo para serem trocados e revisados pelo parceiro) e o tutorial (reunião de orientação realizada antes da SOTi). Associadas à mediação, estão os diários reflexivos (produzidos após cada sessão oral) e os questionários inicial (em que se definem as metas de aprendizagem) e final (em que se avalia a parceria). 
argumentam que a padronização do discurso na SOTi indica que ela pode ser um gênero, o qual pode apresentar diferentes estruturas prototípicas a depender do cenário de aprendizagem ${ }^{6}$ (ARANHA; LEONE, 2016; FOUCHER, 2010) em que a sessão está inscrita; em outras palavras, a depender das características e das tarefas desenvolvidas por cada grupo de participantes.

Entretanto, conforme Rampazzo (2017) declara, há variações na estrutura retórica da SOTi que não podem ser explicadas pelas características dos cenários, isto é, que não têm relação com essas características assumidas pelo grupo de participantes, com a organização da parceria ou com as tarefas desenvolvidas.

Desse modo, neste artigo apresentamos os resultados da investigação da estrutura retórica da sessão oral de teletandem inicial (RAMPAZZO; ARANHA, 2018) e os discutimos a partir do conceito de gênero ocluso (LOUDERMILK, 2007; SWALES, 1996), usado para descrever os gêneros que não são publicamente acessíveis e que, escondidos, podem apresentar variação na estrutura retórica de seus exemplares, com o objetivo de verificar se há relação entre essa variação na estrutura da SOTi e o fato de os participantes não terem acesso, experiência prévia ou conhecimento daquilo que é retoricamente esperado para esse gênero.

Além desta introdução, o artigo divide-se em mais quatro seções e as considerações finais. Adiante, trazemos duas seções em que discutimos os pressupostos teóricos seguidas de uma seção metodológica. Apresentamos então os resultados e sua discussão com base no conceito de gêneros oclusos.

\section{Gêneros textuais e gêneros oclusos}

Dentro da abordagem de Inglês para Fins Específicos, o conceito de gêneros textuais elaborado por Swales (1990) vem sendo utilizado, na área de Linguística Aplicada, para auxiliar estudantes a se inserirem em determinada comunidade científica, sobretudo a acadêmica, e também para a análise de gêneros textuais.

Biasi-Rodrigues, Hemais e Araújo (2009) ressaltam que a concepção de gênero, construída por Swales (1990), pretende combater a ideia de que o gênero seja apenas uma fórmula textual, considerando também o contexto em que ele ocorre. Assim, Swales (1990) apresenta sua definição de gênero como um evento comunicativo utilizado por um grupo de indivíduos, a comunidade discursiva, que se unem a fim de alcançarem objetivos

60 conceito de cenário de aprendizagem é proposto por Foucher (2010) para dar conta daquilo que de fato ocorre em determinada situação de aprendizagem. Aranha e Leone (2016) o adaptam para o contexto de teletandem para descrever a tipologia da interação, os participantes e as tarefas que são desenvolvidas em cada grupo que forma uma parceria. 
públicos e compartilhados. O gênero, nessa perspectiva, é resultado das necessidades dos membros de uma comunidade que criam então estruturas discursivas padronizadas.

Na proposta desse autor, os gêneros são estruturados em movimentos retóricos (moves), os quais correspondem às partes argumentativas de um texto que servem uma função retórica que irá contribuir para que o propósito do gênero seja atingido (SWALES, 1990). Em 2009, Swales declara que tanto os gêneros públicos quanto os oclusos são suscetíveis a uma estruturação em forma de modelo, o qual trará uma previsão daquilo que pode ser encontrado nos textos de determinado gênero. Assim, os movimentos mais comumente encontrados compõem esse modelo que traz a estrutura prototípica de um gênero, isto é, aquela esperada pela comunidade discursiva.

Além dos movimentos, Swales (1990) também inclui os passos (steps), que funcionam como possibilidades dos movimentos retóricos e são, normalmente, opcionais. Pode-se dizer, pois, que os gêneros têm um propósito que será cumprido por meio dos movimentos retóricos, os quais são compostos por passos, escolhidos pelo autor de determinado texto para melhor atingir a função do movimento.

Em relação aos gêneros oclusos, é também Swales (1996) que introduz o conceito. Segundo o autor, alguns gêneros operam para oferecer suporte e validar a construção do conhecimento, os quais são raramente públicos e têm seus exemplares tipicamente oclusos, "escondidos" do público geral, sendo direcionados a pequenos grupos e audiências muito específicas. Swales (1996) oferece como exemplos de gêneros oclusos cartas de apresentação para empregos ou bolsas de estudos, projetos de pesquisa, cartas de recomendação, revisões de artigos científicos (como parte do processo de submissão). Para o autor, essa oclusão traz consequências, dentre as quais destaca o fato de que membros novatos podem experienciar dificuldades para alcançar as expectativas da comunidade, de seu público-alvo, por desconhecerem sua estrutura prototípica. Assim, sem poderem se basear nos exemplares de um gênero ocluso, os autores devem recorrer a outros gêneros e outras situações para construírem seu texto, o que pode levar à maior variação na estrutura dos diversos textos. Em outras palavras, ainda que pertençam ao mesmo gênero, em sua estrutura, podem trazer movimentos distintos ou que se apresentem em outra ordem.

Embora introduza o termo, em seu artigo, Swales (1996) não parece pretender trazer uma discussão sobre os gêneros oclusos e seus traços, mas, sim, apresentar as características de um gênero ocluso, a carta de submissão de artigos enviados à publicação, a fim de auxiliar indivíduos que estejam escrevendo seus exemplares. De modo semelhante, outros poucos autores voltam-se à questão dos gêneros oclusos, como Hyon (2008) e López-Ferrero e Bach (2016), investigando a estrutura retórica dos gêneros selecionados a fim de fornecer recursos aos possíveis autores novatos. Quem traz uma discussão a respeito do termo é Loudermilk (2007), que propõe uma redefinição do conceito ao 
estudar o MBA Thought Essay, um texto curto e reflexivo sobre uma citação da área dos negócios produzido por estudantes de pós-graduação em administração.

Para Loudermilk (2007), a oclusão de um gênero não equivale apenas a um gênero ser público ou ocluso, pois podem existir gêneros parcialmente oclusos. $O$ autor compreende que, se nas circunstâncias normais de funcionamento de uma comunidade, membros novatos não estejam comumente expostos a um gênero, esse gênero é ocluso.

Em sua análise de 57 exemplares do MBA Thought Essay, Loudermilk (2007) conclui que as similaridades entre os textos permitem caracterizá-lo como um gênero. No entanto, os exemplares analisados traziam alto índice de variação retórica, isto é, os diferentes textos possuíam em sua estrutura diferentes movimentos, e o autor não pôde identificar um movimento obrigatório, que aparecesse em todos os exemplares. Diante desse resultado, Loudermilk (2007) levanta a hipótese de que essa variação na estrutura pudesse ser explicada pelo fato de o gênero ser ocluso. Para ele, o Thought Essay apresenta-se assim porque é um gênero nascente que ocorre em uma comunidade com rápida troca de membros. Como consequência, afirma Loudermilk, os autores devem recorrer a convenções discursivas aprendidas anteriormente para estruturarem seu texto. Isso indica, pois, que, quando têm de escrever um texto de natureza oclusa, os autores baseiam-se em outros gêneros que possam conhecer e que identificam como tendo propósitos similares.

A partir de seus resultados, Loudermilk (2007) propõe duas hipóteses: a hipótese da variação e a hipótese do hibridismo. Segundo a hipótese da variação, um gênero ocluso será caracterizado por maior variação léxico-gramatical e estrutural do que gêneros públicos com estrutura formulaica. Como não são facilmente acessíveis, há maior dificuldade no processo de aquisição, já que os autores não têm exemplares para se embasar. A segunda hipótese, do hibridismo, compreende que os gêneros oclusos são nascentes ou funcionam em comunidades com rápida troca entre membros, apresentando, então, características de múltiplos gêneros.

Tem-se, pois, estabelecida a fundamentação teórica sobre gêneros que embasa a discussão feita adiante. Compreende-se o gênero como um evento comunicativo, com estrutura retórica prototípica, utilizado pelos membros de uma comunidade para o cumprimento de seus propósitos. Os gêneros que não são publicamente acessíveis são chamados oclusos e as implicações dessa oclusão resultam em uma estrutura retórica mais flexível, já que os autores, sem terem um modelo para lhes servir de base, devem recorrer a outras experiências e gêneros para produção de seu exemplar. 


\section{A SOTi como um gênero}

Rampazzo e Aranha (2018) apresentam um estudo da estrutura retórica dos 15 primeiros minutos da sessão oral de teletandem inicial. Para tanto, foi realizada uma investigação de dez sessões orais de teletandem inicial nos anos 2011, 2012, 2013 e 2014, disponíveis em uma versão anterior do MulTec (Multimodal Teletandem Corpus) (ARANHA; LOPES, 2019)7. As 10 SOTis são de uma parceria estabelecida entre a UNESP, campus de São José do Rio Preto, e a University of Georgia (UGA), nos Estados Unidos. Sua descrição mais detalhada aparece em Rampazzo e Aranha (2018). Por hora, cumpre saber que, para fins de análise, as sessões dos diferentes anos foram divididas em dois cenários distintos pelas características que apresentavam: no cenário A, estão as sessões de 2011, 2012 e 2013, cujo pareamento aleatório ocorreu na primeira sessão a depender do computador em que os participantes se sentaram; no cenário B, estão as sessões de 2014, cujo pareamento foi prévio e em que os pares trocaram textos antes da SOTi.

As autoras apontam que, no cenário de aprendizagem A, foram encontrados dois movimentos retóricos, o movimento de negociação e o movimento de troca de informações. O movimento de negociação é apresentado como tendo o objetivo de negociar e resolver aspectos da comunicação, a fim de que o propósito identificado para a SOTi seja alcançado, qual seja, a manutenção do contato inicial e sustentação das demais sessões. Rampazzo e Aranha (2018) identificam que duas questões precisaram ser negociadas nesse cenário, as quais correspondem aos passos desse movimento: o passo a corresponde à verificação quanto ao funcionamento do equipamento e ferramentas de comunicação on-line e o passo $b$ corresponde à definição do idioma em que iriam conduzir a primeira parte da sessão. Esses passos, segundo as autoras, são opcionais, pois não estiveram presentes em todas as sessões analisadas.

O movimento de troca de informações foi considerado pelas autoras como obrigatório e o de maior relevância, pois esteve presente em todas as sessões do cenário A e é o mais extenso. Rampazzo e Aranha (2018) destacam que o movimento tem o propósito de fazer com que os parceiros conheçam mais sobre o outro, encontrando pontos em comum e assuntos que sejam do interesse de ambos para estabelecerem e manterem o contato. Em outra publicação, Rampazzo e Aranha (2019b) revisam os passos do movimento de troca de informações e apontam a existência de cinco passos possíveis para esse movimento e não mais nove, quais sejam: (a) apresentações e cumprimentos; (b) informação sobre a vida acadêmica/profissional; (c) informações pessoais - idade, família, interesses, experiências; (d) informações sobre os países e lugares em que vivem; (e) informações sobre o estudo de línguas.

7 A formação desse banco de dados, a versão anterior do MulTec, está descrita em Aranha, Luvizari-Murad e Moreno (2015). 
Em relação ao cenário $B$, as autoras apontam a existência dos movimentos de negociação e de troca de informações. Sobre o movimento de negociação, há um terceiro passo possível para esse cenário, o de busca pelo parceiro correto. Rampazzo e Aranha (2018) explicam que, no cenário B, o pareamento foi feito anteriormente e, quando chegaram ao laboratório de teletandem para a primeira sessão, os participantes não se atentaram aos usuários logados no computador e foram postos em contato com outra pessoa. Houve então a necessidade de negociar com o estudante do outro lado quem era o parceiro correto e onde estava. Além disso, foi encontrado um terceiro movimento, o de discussão sobre o texto. A respeito desse movimento, as autoras comentam que ele é característico do cenário $B$, pois só acontece porque antes da SOTi os parceiros da universidade estadunidense haviam enviado um texto em português aos brasileiros para que esses o revisassem e comentassem na SOTi.

Diante desses resultados, as autoras concluem que a SOTi apresenta indícios de que seja um gênero, pois se trata de um evento comunicativo, com um propósito identificado, que ocorre em uma comunidade teletandem e apresenta regularidade em sua estrutura genérica, isto é, apresenta movimentos e passos comuns aos exemplares estudados. Rampazzo e Aranha (2018) argumentam que a variação no padrão discursivo da SOTi seja resultante das características dos cenários de aprendizagem, ressaltando que, a depender do cenário, movimentos e passos podem estar ausentes ou presentes.

\section{Metodologia}

A presente investigação insere-se no paradigma qualitativo de pesquisa. Os estudos qualitativos são mais flexíveis no sentido de que são abertos à mudança e à incorporação de outros aspectos ao longo do processo (DÖRNYEI, 2007; SANTADE, 2014). Conforme Santade (2014), os estudos qualitativos trabalham com dados de difícil mensuração e, em razão disso, segundo Dörnyei (2007), a amostra é pequena. Os autores também destacam que há uma relação subjetiva entre o pesquisador e o material. A análise, que costuma durar por mais tempo, é essencialmente produto da interpretação do analista.

Quanto aos dados, esclarecemos que são os de Rampazzo e Aranha (2018, 2019b) os 15 primeiros minutos de sete sessões orais de teletandem iniciais ocorridas em 2011, 2012, 2013. Em relação às sessões, deve-se fazer o esclarecimento que, para este estudo, não foram consideradas as três sessões de 2014 que aparecem em Rampazzo e Aranha (2018, 2019b), por elas pertencerem a um cenário distinto, isto é, seu contexto de ocorrência é um pouco distinto, o que, conforme Rampazzo e Aranha (2018), influenciou na estrutura retórica das SOTis quanto à ocorrência de movimentos retóricos e passos. De modo que o objetivo aqui é promover uma discussão que evidencie que pode haver relação entre oclusão de gênero - o fato de o gênero permanecer escondido - e organização retórica, isolamos as sessões que ocorreram no mesmo cenário, com as mesmas características. 
Os dados atualmente compõem o MulTeC (ARANHA; LOPES, 2019), mas, na ocasião deste estudo, ainda pertenciam a uma versão anterior do corpus ${ }^{8}$. Cumpre ressaltar que o MulTeC contém gravações das sessões orais de teletandem ocorridas entre 2012 e 2015 e atualmente parte de suas transcrições, diários de aprendizagem, registros de chat, questionários e textos escritos e revisados pelos estudantes de uma parceria portuguêsinglês estabelecida entre UNESP, campus de São José do Rio Preto, e University of Georgia, nos Estados Unidos.

Ao todo, do presente estudo, são 14 os participantes que formaram sete pares de teletandem: três pares eram de 2011, dois, de 2012 e dois pares de 2013. Os estudantes eram de cursos de graduação - os brasileiros cursavam Letras e os estrangeiros, cursos de graduação distintos. Eles se autoavaliaram entre os níveis B1 e C1 do Quadro Comum Europeu de Referência para Línguas quanto à sua proficiência na língua estrangeira e tinham por volta de 20 anos de idade.

Em relação aos procedimentos de análise, a partir dos resultados apresentados em Rampazzo e Aranha (2018, 2019b), examinamos a ocorrência dos movimentos e passos nas sessões a fim de averiguar a flutuação ou flexibilidade em sua ordem de aparição e também em sua presença ou ausência no corpus. A partir da identificação da variação na estrutura, que não pôde ser explicada pelas características dos cenários de aprendizagem, prosseguimos com uma discussão com base no conceito de gêneros oclusos (LOUDERMILK, 2007; SWALES, 1996).

\section{Resultados e discussão}

Conforme apresentado acima, Rampazzo e Aranha (2018) identificam uma estrutura retórica prototípica para cada cenário das sessões estudadas, defendendo que a variação que ocorre quanto à presença/ausência de movimentos e passos nos diferentes exemplares seja resultante das características dos cenários. No entanto, o estudo não considera a variação na ordem de aparecimento dos movimentos nem as possibilidades de passos para os movimentos.

Além da variação na estrutura da SOTi associada aos cenários de aprendizagem, defendemos que a estrutura retórica da sessão oral de teletandem inicial seja flexível também por apresentar maleabilidade quanto ao emprego dos passos que constituem os movimentos e por não existir uma ordem pré-determinada para que movimentos e passos apareçam na sessão.

8 Os pesquisadores que organizaram o MulTeC optaram por excluir os dados registrados do ano de 2011, pois, quando o banco de dados foi transformado em corpus, grande parte dos arquivos deste ano estavam corrompidos (LOPES, 2019). Considerando que o estudo aqui apresentado foi realizado concomitantemente à organização do MulTeC, optou-se por manter as sessões de 2011 nesta publicação. 
Para ilustrar essa variação na estrutura retórica da SOTi, isto é, no aparecimento de movimentos e passos, apresentamos alguns excertos selecionados ${ }^{9}$. Antes, recordamos que Rampazzo e Aranha (2019b) indicaram a existência de dois movimentos nessas sessões: o de negociação, com os passos de verificação do equipamento e de definição de idioma; e o de troca de informação, com os passos de apresentação e cumprimentos, informações sobre a vida acadêmica/profissional, informações pessoais, informações sobre os países e informações sobre o estudo de línguas.

Em relação à abertura das sessões, nossos dados indicam que não há uma única forma de iniciar o diálogo, pois, enquanto as SOTis 1, 3, 4 e 6 têm início com o movimento de negociação, verificando o funcionamento do equipamento, as SOTis 5 e 7 iniciam-se com a troca de informações (passo de apresentação), e a 2 com informações pessoais.

Os primeiros 15 turnos das SOTis 4 e 7 , por exemplo, ainda que semelhantes quanto ao conteúdo - são dois pares buscando estabelecer um diálogo e se conhecer - organizamse em movimentos retóricos e passos distintos:

E: Can you hear me?

B: yes and you?

E: Good I can hear you fine

B: oh! ok ... we can... can we start eh to talk in English or Portuguese? what you prefer?

E: I.. it does not matter whatever you like

B: oh ok in English [[risos]]

E: in English ok[[risos]]

B: ok ... what's your name?

E: My name is ah UOF29_sm and your name?

B: $19 \mathrm{M} 1$

E: $19 \mathrm{M} 1$

B: YES

E: ok very nice to meet you

B: oh thank you...

9 A fim de facilitar a referenciação às sessões neste trabalho, elas serão chamadas de SOTi 1 , SOTi 2, SOTi 3, SOTi 4, e assim por diante. As sessões 1 a 3 são de 2011, 4 e 5 são de 2012 e 6 e 7 são de 2013. Os turnos são indicados pelas letras B, para o/a participante brasileiro/a, e E, para o/a participante estrangeiro/a. Os nomes foram trocados por códigos, conforme estabelecidos no MulTeC (ARANHA; LOPES, 2019). 
E: so are you a first year student? second year?

(SOTi 4)

E: Olá

B: Olá

E: como vai

B: sim [[as duas riem]] qual que é seu nome?

E: ah ah me llamo ah UOF22

B: UOF22 hm

E: uhum [[incompreensível. problema na gravação]] que?

B: 19F12

E: 19F12?

$\mathrm{B}$ : isso

E: prazer [[risos]]

B: prazer [[digita seu nome no chat]]

E: I9F12 ok [[risos]]

B: quantos anos você tem?

E: ah... eu tem vinte e dois

(SOTi 7)

$\mathrm{Na}$ SOTi 4, os participantes primeiramente confirmam que o equipamento está funcionando - parte do movimento de negociação -, provavelmente como fariam em uma ligação por telefone ou por ferramentas VolP de outros contextos, para então, ainda no movimento de negociação, estabelecerem o idioma em que conversariam, um passo bastante característico deste contexto de aprendizagem telecolaborativo. É somente após as negociações que partem para o movimento de troca de informações, inicialmente trocando seus nomes, no passo de apresentação e cumprimentos, e depois falando sobre suas vidas acadêmicas. O que ocorre na abertura da SOTi 7 é semelhante; também há apresentação e então as participantes passam a trocar informações pessoais, mas a organização retórica é distinta, pois, enquanto nos primeiros turnos da sessão 4 temos dois movimentos retóricos - negociação e troca de informação - e quatro passos - verificação de equipamento, definição do idioma, apresentação e cumprimentos, informações sobre a vida acadêmica, na 7, os primeiros turnos trazem apenas um movimento - a troca de informação - e dois passos - apresentação e cumprimentos e informações pessoais. 
Semelhante no conteúdo aos excertos anteriores, o próximo, da SOTi 5, também tem uma organização retórica distinta. Ainda que a gravação tenha perdido os segundos iniciais da sessão, podemos apontar a seguinte ordem de apresentação dos movimentos nos primeiros 30 turnos: movimento de troca de informação, movimento de negociação, movimento de troca de informação novamente.

[[a gravação parece começar um pouco depois do início da sessão. As duas estão rindo]] E: oh I'm good how are you?

B: I'm good too ah... what's your name?

E: My name is UOF21 what's your name?

B: 19F11

E: nice to meet you

B: nice to meet you too [[sorri e ajeita a câmera]]

E: you're really good at English

B: hm no I am actually I'm terrible [[risos]]

E: I promise I'm worse at Portuguese

B: what?

E: I promise I'm worse at Portuguese than you are in English [[brasileira ri]] I'm so bad [[risos]]

B: It's no problem then I'll help you [[risos]]

E: how many people are in your class? eighteen?

B: ah... I é I think eighteen yes

E: ok

B: what about your class?

E: I think it's the same everyone I think has to be matched ah... to someone there

B: yeah [[ajeita a câmera]] ah... so let's talk ah first in English?

E: ok

B: ok so I don't know what to ask [[risos]]

$\mathrm{E}$ : that's ok ah... so like what time is there?

B: ah... three ah $p$ no... three oh how can I say after after... after the lunch time? [[risos]]

E: oh ah it's three o' clock?

B: isso exactly

E: ok 


\section{B: yeah}

$\mathrm{E}$ : it is one here one p.m.

B: oh

E: do you also say p.m. and a.m? like we do?

B: yeah p.m. and a.m. that's right

(SOTi 5)

Essa ocorrência do movimento de troca de informações também ilustra uma tentativa de estabelecer contato positivo com a outra, fato já apontado em Aranha (2014) e Rampazzo (2017), uma vez que há um elogio à fluência da brasileira em falar o idioma ("you're really good at English), tentativas de preservação de face na ênfase em não saber falar o idioma, e na oferta de ajuda por parte da brasileira ("it's no problem then I'll help you [to learn/ improve]"). A tentativa do contato positivo também pode estar relacionada ao fato de que as estudantes, recorrendo a outros contextos de primeiro contato/encontro - hipótese de hibridismo (LOUDERMILK, 2007), identificarem também ali a necessidade de travar um bom relacionamento.

Há ainda, no excerto acima, quando falam da hora, um questionamento típico de contextos de aprendizagem de línguas ou de contextos de contato interlinguísticos/ interculturais, a pergunta sobre como dizer que já passou do horário de almoço ("how can I say after after the lunch time?"). Essa ocorrência, que talvez possa ser pensada em termos de negociação de idioma, também indica a relação entre a sessão oral de teletandem e outros gêneros (como uma aula) e outros contextos de situação.

Os excertos selecionados parecem evidenciar que existe uma relação entre a SOTi e outros gêneros, textos e contextos e que não há uma ordem fixa para a ocorrência de movimentos e passos. Considerando o conceito de gênero ocluso, aqueles gêneros que não podem ser facilmente acessados ou não têm acesso permitido, além de não apresentarem uma estrutura convencional que pode ser facilmente reconhecida pelos membros novatos de uma comunidade (LOUDERMILK, 2007; SWALES, 1996), compreendemos que essa flexibilidade da SOTi possa estar associada a essa definição.

Assim, defendemos que a SOTi também possa ser compreendida como um gênero ocluso, pois os membros novatos da comunidade teletandem (RAMPAZZO; ARANHA, 2019a) não estão tipicamente expostos a ela antes de sua produção. Ainda que as sessões sejam gravadas e armazenadas em um corpus, este não é público, mas serve à pesquisa acadêmica e é acessado por pesquisadores apenas e mesmo que haja literatura publicada a respeito do teletandem ${ }^{10}$, que contém excertos de sessões orais de

10 A maioria das publicações sobre Teletandem no Brasil estão disponíveis no site teletandembrasil.org. 
teletandem, ela não costuma ser lida pelos estudantes, cujo interesse de participação não é na pesquisa sobre teletandem/telecolaboração, mas, sim, na oportunidade de aprender/ aprimorar seus conhecimentos na língua estrangeira (ARANHA; BRAGAGNOLLO, 2015). Assim, sem terem exemplares aos quais recorrer e sem experiência prévia com o gênero, os participantes de teletandem devem recorrer a outros gêneros que identificam como tendo propósitos similares ao da sessão oral, culminando numa estrutura menos formulaica e com mais variação, o que vai ao encontro do proposto por Swales (1996) e Loudermilk (2007) de que os membros novatos de uma comunidade, ao se depararem com um gênero não publicamente acessível, podem ter mais dificuldade para produzir um texto cuja estrutura seja facilmente reconhecível pelos membros da comunidade.

Ademais, assim como Loudermilk (2007) considera que um gênero ocluso pode apresentar maiores níveis de variação e hibridismo quando é nascente e se forma em uma comunidade com rápida troca de membros, acreditamos que, no teletandem, os gêneros também são nascentes, visto que uma das características da comunidade teletandem (RAMPAZZO; ARANHA, 2019a) é a substituição parcial e contínua de seus membros, pois, a cada semestre, novos estudantes (participantes ou de pós-graduação que atuam como mediadores) passam a fazer parte da comunidade e outros a deixam.

Assim como Rampazzo e Aranha (2018), concordamos que certa variação na estrutura retórica da sessão, isto é, dos movimentos e passos que aparecem nos exemplares, possa ser resultante de alterações nas características dos cenários de aprendizagem ou estar associada ao contexto virtual da comunicação, como quando o passo de negociação de ferramenta do movimento de negociação acontece por algum problema no equipamento. Também reconhecemos que a variação possa estar associada à autonomia dos participantes nesse contexto. Ainda assim, se, por um lado, a flexibilidade na sua estrutura possa estar relacionada à autonomia dos participantes nas tomadas de decisões quanto ao que farão em cada sessão oral, por outro, na sessão oral inicial, também pode estar condicionada ao fato de que os estudantes têm de recorrer a outros gêneros, textos e contextos. Esse repertório no qual têm de se basear para a construção da SOTi depende de suas experiências anteriores e também implica escolhas por serem os participantes autônomos em seu processo de aprendizagem. De tal modo, argumentamos que, conquanto a estrutura da sessão inicial seja flexível por conta do princípio da autonomia no teletandem, esse fato não exclui a hipótese de hibridismo (LOUDERMILK, 2007), isto é, que, sendo oclusa a SOTi, os estudantes devem se apoiar em (e fazer escolhas das) experiências anteriores, as quais, por sua vez, diferem/variam de um indivíduo a outro.

\section{Considerações finais}

Neste trabalho, apresentamos a estrutura retórica da sessão oral de teletandem inicial, a qual compreendemos ser um dos gêneros que circulam no contexto de teletandem, para que pudéssemos verificar se havia relação entre a variação na sua estrutura retórica e o fato de os participantes não terem tido acesso ou experiência prévia com a SOTi. Para 
tanto, apresentamos a definição de gênero ocluso e defendemos que a SOTi possa ser considerada oclusa, visto que, ainda que sejam apresentados fragmentos de sessões orais de teletandem nas teses, dissertações, artigos e capítulos de livros já publicados, dificilmente os estudantes acessarão tais textos, considerando que seu propósito ao participar do teletandem não é a pesquisa acadêmica. Além disso, entendemos que a SOTi, em sua totalidade, não é publicamente acessível e, portanto, os participantes do teletandem não podem recorrer a um modelo formulaico para a construção de seus exemplares. Ao contrário, cada participante se apoia em gêneros e experiências anteriores, as quais podem variar e, em razão disso, levar à flexibilização na estrutura da sessão oral.

Argumentamos aqui que os novos membros de uma comunidade podem ter mais dificuldade em se tornarem membros bem-sucedidos na comunidade se não estão cientes da estrutura retórica esperada para um gênero e, portanto, alcançar seus propósitos. $\mathrm{O}$ alto grau de flutuação na estrutura de um gênero pode ainda indicar um processo de padronização. No caso da sessão oral de teletandem inicial, esse processo tende a ser ainda mais lento, uma vez que não há indícios de que a SOTi poderá eventualmente ser de acesso público e há rápida troca de membros na comunidade teletandem.

Por fim, nosso trabalho parece confırmar as hipóteses de variação e hibridismo apontadas por Loudermilk (2007) para os gêneros oclusos. A sessão oral de teletandem inicial não só apresenta maior variação na organização dos movimentos e possibilidade de passos, como também apresenta características de outros gêneros, tais como, o diálogo informal entre amigos e pessoas que acabaram de se conhecer, provavelmente porque os participantes recorrem a gêneros usados nessas ocasiões para a construção da sessão, reconhecendo, tanto na SOTi quanto nos encontros informais, propósitos semelhantes, tal como o de estabelecer um primeiro contato positivo.

Uma vez que a pesquisa aqui apresentada é apenas um recorte e uma discussão inicial a respeito dos gêneros oclusos e teletandem/telecolaboração, futuros trabalhos poderiam voltar-se à questão a fim de averiguar se a variação na estrutura retórica da sessão oral de teletandem inicial mantém-se para além dos 15 primeiros minutos. Além disso, outros instrumentos de pesquisa poderiam ser explorados, tais como, entrevistas com os estudantes, para elucidar em que gêneros/textos os estudantes se apoiam para construção da SOTi. 


\section{REFERÊNCIAS}

ARANHA, S. Os gêneros na modalidade de teletandem institucional integrado: a primeira sessão de interação. In: NASCIMENTO, E. L.; ROJO, R. H. R. (org.). Gêneros de texto/discurso e os desafios da contemporaneidade. Campinas: Pontes Editores, 2014. p. 97-117.

ARANHA, S.; BRAGAGNOLLO, R. M. Genres and teletandem: Towards a successful relationship. In: LIMA-LOPES, R. E.; FISCHER, C. R.; GAZOTTI-VALIM. M. A. (org.). Perspectivas em línguas para fins especificos: Festchrift para Rosinda Ramos. Campinas: Pontes Editores, 2015. p. 81-91.

ARANHA, S.; CAVALARI, S. M. S. A trajetória do projeto Teletandem Brasil: da modalidade Institucional Não-Integrada à Institucional Integrada. The ESPecialist, v. 35, n. 2, p. 183201, 2014. Disponível em: https://revistas.pucsp.br/index.php/esp/article/view/21467. Acesso em: 27 ago. 2018.

ARANHA, S.; LEONE, P. DOTI: Databank of Oral Teletandem Interactions. In: JAGER, S.; KUREK, M. (ed.). New directions in telecollaborative research and practice: selected papers from the second conference on telecollaboration in higher education. Dublin: Researchpublishing.net, 2016, p. 1-6. Disponível em: https://files.eric.ed.gov/fulltext/ED571372. pdf. Acesso em 27 ago. 2018.

ARANHA, S.; LEONE, P. State of the arts and DOTI - Data of Oral Teletandem Interaction phase of development. In: FISER, D.; BEIBWENGER, M. (ed.). Investigating computermediated communication corpus-based approachers to language in the digital world. Ljubljana: Ljubljana University Press, 2017. p. 172-190.

ARANHA, S.; LOPES, Q. Moving from an internal databank to a sharable multimodal corpus: the MulTeC case. The Especialist, v. 40, n. 1, 2019 [não paginado].

ARANHA, S.; LUVIZARI-MURAD, L.; MORENO, A. C. A criação de um banco de dados para pesquisas sobre aprendizagem via teletandem institucional integrado (TTDii). Revista (Con)textos Linguísticos (UFES), v. 9, p. 274-293, 2015. Disponível em: http://periodicos. ufes.br/contextoslinguisticos/article/view/9633. Acesso em: 27 ago. 2018.

BIASI-RODRIGUES, B.; HEMAIS, B.; ARAÚJO, J. C. Análise de gêneros na abordagem de Swales: princípios teóricos e metodológicos. In: BIASI-RODRIGUES, B.; ARAÚJO, J. C.; SOUSA, S. C. T. (org.). Gêneros textuais e comunidades discursivas: um diálogo com John Swales. Belo Horizonte: Autêntica Editora. 2009. p. 17-32. 
BRAMMERTS, $\mathrm{H}$. Tandem language learning via the internet and the International E-Mail Tandem Network. In: LITTLE, D.; BRAMMERTS, H. (ed.). A Guide to Language Learning in Tandem via the Internet. CLCS Occasional Paper, 46. Dublin: Trinity College, 1996. p. 9-21.

CAVALARI, S. M. S.; ARANHA, S. Teletandem: integrating e-learning into the foreign language classroom. Acta Scientiarium: Language and Culture, 2016. Disponível em: https://www.researchgate.net/publication/310625664_Teletandem_Integrating_elearning_into_the_foreign_language_classroom. Acesso em: 27 ago. 2018.

DÖRNYEI, Z. Research Methods in Applied Linguistics: Quantitative, Qualitative and Mixed Methodologies. Oxford: Oxford University Press, 2007.

EVANGELISTA, M. C. R. G.; SALOMÃO, A. C. B. Mediation in Teletandem: From face-to-face sessions to reflective journals. Pandaemonium, v. 22, n. 36, p. 153-177, 2019.

FOUCHER, A. Didactique des Langues-Cultures et Tice: scénarios, tâches, Interactions. Tradução Deise Marinoto. Education. Université Blaise Pascal-Clermont-Ferrand II, 2010. p. 81-90. Disponível em: https://tel.archives-ouvertes.fr/tel-00812813/document. Acesso em: 27 ago. 2018.

HAUCK, M.; YOUNGS, B. L. Telecollaboration in multimodal environments: the impact on task design and learner interaction. Computer Assisted Language Learning, v. 21, n. 2, p. 87124, 2008. Disponível em: http://oro.open.ac.uk/8482/. Acesso em: 27 ago. 2018.

HYON, S. Convention and inventiveness in an occluded academic genre: A case study of retention-promotion-tenure reports. English for Specific Purposes, v. 27, p. 175-192, 2008. Disponível em: https://www.sciencedirect.com/science/article/pii/S0889490607000361. Acesso em: 27 ago. 2018.

LOPES, Q. B. MulTeC: a construção de um corpus multimodal em teletandem. 2019. Tese (Doutorado em Estudos Linguísticos) - Instituto de Biociências, Letras e Ciências Exatas, Universidade Estadual Paulista, São José do Rio Preto, 2019.

LÓPEZ-FERRERO, C.; BACH, C. Discourse analysis of statements of purpose: Connecting academic and professional genres. Discourse studies, v. 18, n. 3, p. 286-310, 2016. Disponível em: http://journals.sagepub.com/doi/abs/10.1177/1461445616634553. Acesso em: 27 ago. 2018. 
LOUDERMILK, B. C. Occluded academic genres: An analysis of the MBA Thought Essay. Journal of English for Academic Purposes, v. 6, p. 190-205, 2007. Disponível em: https:// www.sciencedirect.com/science/article/pii/S1475158507000343. Acesso em: 27 ago. 2018.

O'DOWD. R. Telecollaborative networks in university higher education: overcoming barriers to integration. The Internet and Higher Education, v. 18, p. 47-53, 2013. Disponível em: https://www.sciencedirect.com/science/article/pii/S1096751613000110. Acesso em 27 ago. 2018.

RAMPAZZO, L. Gêneros textuais e telecolaboração: uma investigação da sessão oral teletandem inicial. 2017. Dissertação (Mestrado em Estudos Linguísticos) - Instituto de Biociências, Letras e Ciências Exatas, Universidade Estadual Paulista, São José do Rio Preto, 2017.

RAMPAZZO, L.; ARANHA, S. Revisiting the concept of community to foster its applicability to telecollaboration. Alfa, São Paulo, v. 63, n. 2, p. 373-396, $2019 a$.

RAMPAZZO, L.; ARANHA, S. Telecollaboration and genres: a new perspective to understand language learning. Journal of Virtual Exchange, Dublin, v. 2, p. 1-22, 2019b.

RAMPAZZO, L.; ARANHA, S. A sessão oral de teletandem inicial: a estrutura retórica do gênero. DELTA: Documentação e Estudos em Linguística Teórica e Aplicada, São Paulo, v. 34, n.1, p. 449-473. 2018.

SANTADE, M. S. B. A metodologia de pesquisa: instrumentais e modos de abordagem. In: SIMÕES, D.; GARCÍA, F. (org.). A pesquisa científica como linguagem e práxis. Rio de Janeiro: Dialogarts, 2014.

SILVA, J. M. Projeto Teletandem Brasil: as relações entre as comunidades virtuais, as comunidades discursivas e as comunidades de prática. 2012. Dissertação (Mestrado em Estudos Linguísticos) - Instituto de Biociências, Letras e Ciências Exatas, Universidade Estadual Paulista "Júlio de Mesquita Filho", São José do Rio Preto, 2012. Disponível em: http://bit.ly/2NqkWyT. Acesso em: 27 ago. 2018.

SWALES, J. M. Genre analysis: English in academic and research settings. Cambridge: Cambridge University Press, 1990. 
SWALES, J. M. Occluded Genres in the Academy: The Case of the Submission Letter. In: VENTOLA, E.; MAURANEN, A. Academic writing: intercultural and textual issues. Amsterdam: John Benjamins, 1996. p. 45-58. Disponível em: http://bit.ly/2qPM8zp. Acesso em: 27 ago. 2018.

SWALES, J. Sobre modelos de análise do discurso. In: BIASI-RODRIGUES, B.; ARAÚJO, J. C.; SOCORRO, C. T. S. (org.). Gêneros textuais e comunidades discursivas: um diálogo com John Swales. Belo Horizonte: Autêntica Editora, 2009. p. 33-46.

TELLES, J. A. Projeto Teletandem Brasil: Línguas Estrangeiras para Todos - Ensinando e Aprendendo línguas estrangeiras in-tandem via MSN Messenger. Faculdade de Ciências e Letras, Universidade Estadual Paulista "Júlio de Mesquita Filho", Assis, 2006.

VASSALLO, M. L.; TELLES, J. A. Foreign language learning in-tandem: theoretical principles and research perspectives. The ESPecialist, v. 25, n. 1, p. 1-37, 2006.

ZAKIR, M. A. Cultura e $(m)$ telecolaboração: uma análise de parcerias de teletandem institucional. 2015. Tese (Doutorado em Estudos Linguísticos) - Instituto de Biociências, Letras e Ciências Exatas, Universidade Estadual Paulista "Júlio de Mesquita Filho", São José do Rio Preto, 2015. Disponível em: https://repositorio.unesp. br/handle/11449/138417. Acesso em: 27 ago. 2018. 